\title{
1 Canopy interactions and physical stress gradients in subtidal communities
}

3 Scott Bennett ${ }^{1, \mathrm{a}^{*}}$, Thomas Wernberg ${ }^{1}$, Thibaut de Bettignies ${ }^{1}$, Gary A. Kendrick ${ }^{1}$, Robert J.

4 Anderson ${ }^{2,3}$, John J. Bolton ${ }^{3}$, Kirsten Rodgers ${ }^{4}$, Nick Shears ${ }^{4}$, Jean-Charles Leclerc ${ }^{5,6}$,

5 Laurent Lévêque ${ }^{5,7}$, Dominique Davoult ${ }^{5,6}$ and Hartvig C. Christie ${ }^{8}$

6

$7 \quad{ }^{1}$ School of Plant Biology \& UWA Oceans Institute, University of Western Australia, 39

8 Fairway, Crawley 6009, WA, Australia.

$9 \quad{ }^{2}$ Seaweed Research Unit, Department of Agriculture, forestry and Fisheries, Pvt Bag X2,

10 Roggebaai 8012, South Africa

$11{ }^{3}$ Department of Biological Sciences and Marine Research Institute, University of Cape

12 Town, Rondebosch 7701, South Africa

$13{ }^{4}$ Leigh Marine Laboratory, Institute of Marine Science, University of Auckland, PO Box

14 349, Warkworth 0941, New Zealand

$15{ }^{5}$ Sorbonne Universités, UPMC Univ Paris 6, Station Biologique, Place Georges Teissier, 16 F.29680 Roscoff, France

$17{ }^{6}$ CNRS, UMR 7144, Station Biologique, Place Georges Teissier, F.29680 Roscoff, France

$18{ }^{7}$ CNRS, FR 2424, Station Biologique, Place Georges Teissier, F. 29680 Roscoff, France

$19{ }^{8}$ Section for Marine Biology, Norwegian Institute for Water Research, Oslo, Norway

20 a Present address: Department of Environment and Agriculture, Curtin University, Bentley, 21 WA 6102, Australia 
23 Email: scott.bennett1@curtin.edu.au, thomas.wernberg@uwa.edu.au,

thibaut.debettignies@uwa.edu.au,gary.kendrick@uwa.edu.au,robert.anderson@uct.ac.za, john.bolton@uct.ac.za,k.rodgers@auckland.ac.nz,n.shears@auckland.ac.nz,jcleclerc@sbroscoff.fr, leveque@sb-roscoff.fr, dominique.davoult@sb-roscoff.fr, hartvig.christie@niva.no

27 Running title: Canopy interactions in subtidal communities

28 Keywords: facilitation, competition, kelp, stress gradient hypothesis, species interactions,

29 Allee effects, seaweed

30 Type of article: Letter

31 Number of words: Abstract $=145$, main text (excluding abstract, acknowledgements,

32 references, table and figure legends) $=4,898$, text boxes $=0$, references $=50$

33 Number of figures $=3$, Number of Tables $=2$, Number of Text boxes $=0$

34 Corresponding author: Scott Bennett, Present address: Department of Environment and

35 Agriculture, Curtin University, Bentley, WA 6102, Australia P: +614 00434898.

36 E:scott.bennett1@curtin.edu.au

37 Statement of authorship: S.B and T.W conceived the idea and decided upon the sampling design. All authors help with data collection and logistics. S.B wrote the manuscript with contributions from all authors. 


\section{Abstract:}

42 Species interactions are integral drivers of community structure and can change from competitive to facilitative with increasing environmental stress. In subtidal marine ecosystems, however, interactions along physical stress gradients have seldom been tested. We observed seaweed canopy interactions across depth and latitudinal gradients to test whether light and temperature stress structured interaction patterns. We also quantified interspecific and intra-specific interactions among nine subtidal canopy seaweed species across three continents to examine the general nature of interactions in subtidal systems under low consumer pressure. We reveal that positive and neutral interactions are widespread throughout global seaweed communities and the nature of interactions can change from competitive to facilitative with increasing light stress in shallow marine systems. These findings provide support for the stress gradient hypothesis within subtidal seaweed communities and highlight the importance of canopy interactions for the maintenance of subtidal marine habitats experiencing environmental stress.

\section{Introduction:}

Species interactions can be important drivers of community structure and function (Kikvidze et al. 2005) from local to global scales (Cavieres et al. 2014) and have the capacity to buffer ecosystems against stressful environmental conditions that could otherwise lead to habitat loss or fragmentation (Bruno et al. 2003). Species interactions can change along physical and biotic stress gradients from competitive in benign conditions to become increasingly facilitative under stressful conditions, as the benefits of stress amelioration from neighbours begins to outweigh the costs of living together (SGH: Stress Gradient Hypothesis, Bertness \&

64 Callaway 1994). For terrestrial plants, the SGH has received strong empirical support within 
a wide range of community types across physical, resource and biotic stress gradients (He et al. 2013). Among subtidal marine plants (herein considered as seaweeds and seagrasses), by contrast, the nature of species interactions in response to changes to the physical environment are less well resolved (Bulleri 2009).

The physical environment has long been recognised as a strong driver of species interactions in subtidal ecosystems (Kitching 1941; Reed \& Foster 1984; Witman 1987; Dayton et al. 1999), however, few studies have examined whether the nature of species interactions change predictably in response to physical stress gradients (Bulleri 2009). Among the few studies that have examined physical gradients in subtidal systems, changes to abiotic conditions appear to have strong influence on the nature of interactions (Wernberg et al. 2010; Bulleri et al. 2011; Bennett \& Wernberg 2014). Bulleri et al. (2011), for example demonstrated that the nature of interactions between tube building gastropods and seaweed was influenced by both physical (sediment deposition) and biotic (grazer density) gradients. Wernberg et al. (2010) and Bennett and Wernberg (2014), both demonstrated that canopy-recruit interactions can become increasingly positive or remain positive toward warmer latitudes along a latitudinal climatic gradient, although the exact role of the canopy in modifying the physical environment in these two studies remains unclear.

To date, positive species interactions in subtidal communities have been primarily reported in response to high consumer pressure (Bulleri 2009) whereby chemical defences (Hay 1986; Stachowicz \& Hay 1999), mechanical defences (Anderson et al. 1997) and physical barriers (Bennett et al. 2010) reduce the incidence of predation on beneficiary species. Other important drivers of positive interactions in subtidal communities include demographic constraints, (i.e. Allee effects), whereby population fitness displays positive density 
dependence (Berec et al. 2007) and resource availability, whereby benefactors can increase the nutrient availability for beneficiary species (Peterson \& Heck 2001).

Physical gradients are prevalent in the subtidal, most notably from sunlight attenuation with depth (Duarte 1991), water velocity which decreases with depth and increases with wave exposure (Siddon \& Witman 2003), and temperature which usually decreases with increasing depth and latitude (Smale \& Wernberg 2009). While light is often considered to be a limiting resource underwater, excessive light can become stressful for organisms (Altamirano et al. 2004) and therefore any modification of these conditions could promote facilitation. Within the photic zone, seaweed canopies are dominant habitat formers of benthic marine ecosystems globally and dramatically alter the physical environment for organisms living within them. Light levels are altered by all canopy types ranging from the surface canopies of the giant kelp, Macrocystis pyrifera (Reed \& Foster 1984) to subsurface canopies of species such as Ecklonia radiata (Wernberg et al. 2005). Water velocities can also be modified by seaweed canopies, reducing the amount of drag an organism experiences by over $80 \%$ in dense canopies (Johnson 2001). Under low flow velocities, individuals can grow larger, than in high flow areas (de Bettignies et al. 2013a) thereby providing a mechanism for subtidal canopies to promote facilitation in high-flow environments. Temperature conditions in contrast, while critical to the distribution and abundance of seaweeds (Lüning 1984) are assumed to be largely unaffected by subtidal canopy conditions due to the high mixing of seawater (Kordas et al. 2011). Nevertheless, dense shallow water canopies have been observed to reduce ambient temperatures, suggesting that temperature stress amelioration could occur in high density canopies (Critchley et al. 1990). 
111 Here we test the nature of seaweed canopy interactions in subtidal marine ecosystems in

112 response to depth and latitudinal gradients in light and temperature stress respectively. We

113 also examine general patterns in the nature of canopy interactions under low consumer

114 pressure in the subtidal by observing inter-specific and intra-specific interactions among nine

115 dominant canopy formers across three continents. This study advances our understanding of

116 how subtidal canopies function under low consumer pressure and in response to increasing

117 abiotic stress. In doing so, we broaden the generality of the stress gradient hypothesis to

118 incorporate subtidal light climates and reveal widespread importance of positive canopy

119 interactions in subtidal communities.

Methods:

Depth experiment:

123

124

Intra-specific interactions within kelp, Ecklonia radiata, canopies were measured along a depth gradient in Hamelin Bay, south-western Australia $\left(34^{\circ} \mathrm{S}, 115^{\circ} \mathrm{E}\right)$, during Austral summer, December 2013 to February 2014. Nine reefs (sites) each separated by at least 1.8 $\mathrm{km}$, were chosen along a depth gradient (3, 5, 6, 9, 11, 12, 16, 18 and $19 \mathrm{~m}$ depth). Reefs in the region are exposed to relatively small tidal fluctuations $(<0.5 \mathrm{~m})$, meaning kelps can live on very shallow reefs and experience almost full sunlight conditions while remaining constantly submerged. At the other end of the spectrum, kelps in south-western Australia live down to 50-60 m depth where they no longer form canopies but grow as solitary individuals, presumably due the limiting light availability (Marzinelli et al. 2015). Reefs used in our study were in the upper third of kelp depth distribution where light is not a limiting resource (Staehr \& Wernberg 2009), but could form a 'non-resource' stress gradient from benign deeper reefs (16-20 m) to stressful high-light shallow reefs (2-5 m). All reefs had relatively flat, 'simple' 
topography and were dominated by dense, closed Ecklonia radiata canopies (8-12 sporophytes $\mathrm{m}^{-2}$, following Bennett $\&$ Wernberg 2014). Within each site, 30 adult kelps were haphazardly selected and tagged around the stipe. Of those, 15 individuals were left to grow inside the unaltered canopy and 15 had all surrounding neighbours removed within a $1 \mathrm{~m}$ radius of the tagged kelp. Experimental setup was conducted by divers on SCUBA.

Kelp growth was measured over two months using the hole-punch method (de Bettignies et al. 2013b). Two holes were punched in the centre of the primary lamina, $5 \mathrm{~cm}$ and $10 \mathrm{~cm}$ above the junction between the stipe and the primary lamina. Thallus extension after the two months was quantified in the laboratory by measuring the distance between the two holes and the stipe-lamina-junction and subtracting the initial $10 \mathrm{~cm}$ distance. The kelp was then sliced into segments at $5 \mathrm{~cm}$ intervals along the length of the primary lamina, with each segment incorporating both primary lamina and lateral (secondary blades coming off the primary lamina) tissue. The segment with the greatest biomass in the first $30 \mathrm{~cm}$ above the stipelamina-junction was used to calculate biomass accumulation (BA, or kelp growth) as $\mathrm{BA}=$ $\mathrm{L}_{\text {ext }} \cdot \mathrm{W}_{\mathrm{F}} / 5 \mathrm{~T}$ where $\mathrm{L}_{\text {ext }}$ is lamina extension $(\mathrm{cm}), \mathrm{W}_{\mathrm{F}}=$ fresh weight $(\mathrm{g})$ of the heaviest segment and $\mathrm{T}$ is the number of growth days between punching the holes and collecting the kelp (de Bettignies et al. 2013b).

Differences in biomass accumulation patterns between plants with and without neighbours were converted to a Relative Interaction Index (RII, Armas et al. 2004) to compare the nature and intensity of interactions among sites of different depths. RII was calculated as RII = $\left(\mathrm{BA}_{\mathrm{w}}-\mathrm{BA}_{0}\right) /\left(\mathrm{BA}_{\mathrm{w}}+\mathrm{BA}_{0}\right)$, where $\mathrm{BA}_{0}=$ biomass accumulation (g.FW. $\left.\mathrm{d}^{-1}\right)$ without neighbours and $\mathrm{BA}_{\mathrm{w}}=$ biomass accumulation with neighbours. The RII ranges between -1 and 1 and presents a continuous scale for competitive $(-1 \leq x<0)$ and facilitative $(0 \leq x<1)$ interactions that is symmetrical around zero. Patterns in RII along the depth gradient were analysed by comparing a set of polynomial models of degree $=1,2,3$ using Akaikes Information 

displayed the best relationship to the data. Linear results are presented as they provided the best fit of the date and because AIC values differ by less than 2 units between the models (Anderson 2008).

Kelp tissue 'health' was measured by quantifying the cover of epiphytic algal growth on the lower and upper laterals of each kelp. Epiphyte cover was quantified by haphazardly selecting four lower and four upper laterals from each replicate kelp and photographing them. Each image was then analysed by randomly allocating points to the image and counting the presence/absence of epiphytes under 15 random points on each lateral ( $n=120$ points per kelp) using CPCe V4.1 software (Kohler \& Gill 2006). Epiphyte counts on each lateral were then used to calculate the mean percent epiphyte cover per kelp.

At the end of the experimental period the physiological acclimation of the depth and canopy treatments to experimental conditions were measured by quantifying oxygen evolution of kelps using photorespirometry chambers in situ under their respective experimental settings (following Rodgers et al. In press). Photosynthetic rates were measured at ambient light levels in situ, and respiration rates were measured in the dark. A detailed description of the methods can be found in Appendix S1(a).

Temperature $\left({ }^{\circ} \mathrm{C}\right.$ ) and illuminance (Lux) was measured in situ at 15 min intervals in each site throughout the course of the experiment using data loggers (onset $\mathrm{HOBO}^{\circledR}$ data loggers Pendant Temp-Light, Onset Computer Corporation). Hobo pendant loggers provide light intensity measurements that accurately reflect photosynthetically active radiation (PAR) measurements taken in underwater marine environments, and enable cost effective deployment across multiple (18) experimental treatments (Long et al. 2012). At each site, one logger was attached to a dive weight and placed within the kelp canopy to record canopy 
conditions. A second logger was placed in the open adjacent to the canopy-free treatments.

Daily minimum, maximum and mean temperatures for each site were extracted and averaged among days for the duration of the experiment to compare between depth and canopy treatments. For light, mean, maximum, and the standard deviation of light levels between the hours of 0800 - 1600 were extracted for the first 14 days of the experiment. Fouling on the logger meant that recordings taken after this time were not representative of ambient conditions. Daily values were averaged among the first 14 days to compare among depth and canopy treatments. Variation in water velocities among sites was measured using gravitational data loggers (HOBO Pendant G, Onset Computer Corporation, Bourne, MA, USA) mounted on a hemispherical float (110 mm diameter) and attached to a $750 \mathrm{~mm}$ length of nylon rope (12 mm thickness) which was anchored to the bottom (Evans \& Abdo 2010). The accelerometer was laid flat on the float such that only 2 channels were used $(\mathrm{x}, \mathrm{y})$ to account for horizontal acceleration (c.f. H2O motion V2 design; Evans \& Abdo 2010). The logger was set to record the acceleration $\left(\mathrm{ms}^{-2}\right)$ at 2 minute intervals over the duration of the experiment. At each site the relative water movement (WM) was expressed as the mean of the 95th percentile WM over the duration of the experiment.

Kelp growth, mean epiphyte cover, temperature and illuminance were compared between canopy treatments along the depth gradient using an Analysis of Covariance (ANCOVA) with 'canopy-treatment' as a categorical grouping factor (two levels: canopy and canopyfree) and depth as a continuous covariate. Epiphyte cover data was arcsin-square root transformed and illuminance data was log10 transformed to address the non-normality and heteroscedasticity of the data, after examining the residual vs fitted value plot and the Q-Q plot. Growth and temperature data met assumptions of normality and homoscedasticity and no transformations took place. 
210 Latitudinal comparisons of intra-specific interactions took place along a $\sim 2^{\circ} \mathrm{C}$ temperature

211 gradient in south-western Australia, on two occasions during Austral spring (August -

212 October 2012) and summer (January - March 2013), representing the periods of highest kelp

213 growth rates and temperature stress respectively (de Bettignies et al. 2013b). Interaction

214 experiments were conducted at nine sites (9-12m depth) across three locations, Hamelin Bay

$215\left(34^{\circ} \mathrm{S}\right)$, Marmion $\left(32^{\circ} \mathrm{S}\right)$ and Jurien Bay $\left(30^{\circ} \mathrm{S}\right)$, spanning the warmest third of E. radiata's

216 latitudinal distribution in Australia $\left(\sim 43^{\circ} \mathrm{S}-29^{\circ} \mathrm{S}\right)$. This north-south trending coastline is

217 characterised by the warm poleward flowing Leeuwin Current, consistent limestone habitat,

218 low nutrient conditions and a stable ocean climate gradient (Smale \& Wernberg 2009).

219

Within each site, kelp growth, RII and environmental measurements in canopy and canopyfree treatments were recorded as described for the depth experiment. Tissue health was quantified for the summer sampling period only, by estimating the percentage cover on 4 replicate laterals from each of the lower, middle and upper sections of each kelp. Patterns in RII between spring and summer, across the latitudinal gradient were examined with an ANCOVA, using time as a fixed factor (two levels: spring and summer) and latitude as a continuous covariate. ANCOVA assumptions were checked as described for the depth experiment and no transformation took place. Mean epiphyte cover on kelps, temperature and illuminance was compared between canopy treatments along the latitudinal gradient using an ANCOVA with 'canopy-treatment' as a categorical grouping factor (two levels: canopy and canopy-free) and latitude as a continuous covariate. Epiphyte cover data was arcsin-square root transformed and illuminance data was square-root transformed to address the nonnormality and heteroscedasticity of the data. 
234 The nature of inter-specific and intra-specific interactions among different subtidal canopy

235 species experiencing low consumer pressure were tested for nine dominant canopy species (4 kelps and 5 fucoids) from Australia, South Africa, Norway and France (Table S1). Sites varied between regions ranging from shallow (3 - $4 \mathrm{~m})$ tropical Sargassum beds in Australia, to deeper (10 - $12 \mathrm{~m}$ ) cool temperate kelp forests in Norway (Table S1). Sites were selected that had dense closed seaweed canopies (Table S2) and low apparent herbivore consumer pressure. Herbivore pressure was measured during the canopy growth experiments by comparing consumption rates between canopy and canopy-free treatments (kelp) and caged controls (Sargassum only, Appendix S1b, Fig. S1). Intra-specific interaction strength was tested by haphazardly selecting and tagging 30 plants, of which 15 individuals were left to grow inside the canopy and 15 had the surrounding canopy removed, by clearing a circular area around the tagged seaweed as described for the depth experiment. Clearing sizes varied in accordance with the size of the seaweed, ensuring that no contact or shading by the canopy occurred. Inter-specific interactions using Laminaria pallida and Sargassum decurrens as beneficiary species were tested using the same methodology described for intra-specific interactions. Inter-specific interactions using Ecklonia radiata, Scytothalia dorycarpa, Arthrophycus sp. and temperate Sargassum sp. as beneficiaries were conducted by translocating individuals into the desired canopy and canopy-free treatments due to low natural densities at the study sites. All translocations occurred within the same site and depth contour from which they were collected, without removing the seaweed from the water (Appendix S1c). For both inter-specific and intra-specific interactions kelp (Ecklonia radiata, E. maxima, Laminaria pallida and L. hyperborea), growth rates were measured using the hole-punch method and converted to RII as described for the depth experiment. For the five fucoid species (temperate Scytothalia dorycarpa, Arthrophycus sp and Sargassum sp, tropical 

(L) and circumference (C) of tagged individuals at the beginning and end of the experiment, and converting the measurement to fresh weight $\left(\mathrm{W}_{\mathrm{F}}\right)$ using the equation $\mathrm{W}_{\mathrm{F}}=\mathrm{LC}^{2}$

261 (following Aberg 1990). Each individual was also collected at the end of the experiment and weighed in the laboratory to the nearest $0.1 \mathrm{~g}$ to calibrate the biomass conversion model for each species (Fig. S2). A detailed description of the site and species specific methods can be found in Appendix S1c.

\section{Results:}

Intra-specific interactions at different depths

Intra-specific interactions between Ecklonia radiata and the canopy changed from net competitive to facilitative from deep to shallow along a $20 \mathrm{~m}$ depth gradient $\left(\mathrm{F}_{1,7}=7.32, \mathrm{p}=\right.$ 0.030 , adjusted $\mathrm{R}^{2}=0.442$; Fig. $1 \mathrm{a}$ ). In sites deeper than $8 \mathrm{~m}$, kelp growth rates were generally higher in canopy-free treatments, whereas shallower than $8 \mathrm{~m}$ growth rates were consistently higher within the canopy (Fig. S3). This transition in growth rate was coupled with a dramatic increase in epiphyte loading in shallow canopy-free treatments $(73.2 \pm 9 \%$ of total thallus area) compared to shallow canopy treatments $(2.1 \pm 0.6 \%$ of total thallus area) and all deep treatments (Fig. 1b; Table 1). Interestingly, after the two month experimental period, short term photosynthesis and respiration rates measured in the photorespirometry chambers resulted in positive RII in five out of seven sites tested, with deep sites recording the highest RII values (Fig. S4a). Large differences in interaction strength (RII) in deep sites were driven by high photosynthetic rates and low respiration in canopies compared to canopy-free treatments (Fig. S4b - c). In shallow sites, photosynthetic rates were higher than 
expected for canopy-free treatments, which may be attributable to the dense epiphytic cover growing on the thallus of canopy-free kelps.

Both light and temperature significantly increased with decreasing depth, however only light was consistently modified by the canopy and represented a stress gradient per se (He \& Bertness 2014, Fig. 1c - d, Table 1). Shallow canopy-free treatments had ten-fold higher mean light levels (14,408 \pm 780 Lux) than shallow canopy treatments (1352 \pm 329 Lux), and four-fold higher levels than deep canopy-free treatments (3673 \pm 164 Lux). This pattern was also consistent for maximum daily illuminance and standard deviation in daily illuminance (Fig. S5). Temperature conditions by contrast changed more uniformly with depth in both canopy and canopy-free treatments. Canopy treatments had significantly lower temperatures than canopy-free treatments, but the difference was not uniform among sites, and small (maximum difference between canopy and canopy-free treatments $=0.29^{\circ} \mathrm{C}$, mean difference $=0.07^{\circ} \mathrm{C} \pm 0.04^{\circ} \mathrm{C}$ ) in comparison to temperature differences along the depth gradient (maximum difference between depths $=0.73^{\circ} \mathrm{C}$, Fig. 1d, Table 1). Furthermore the temperature gradient was relatively benign compared to the seasonal temperature range experienced by kelps in the area $\left(16-23^{\circ} \mathrm{C}\right)$ and is therefore not considered to represent a stress gradient per se. No clear depth pattern in relative water motion (WM) was observed among the nine sites. Mean 95th percentile relative WM in both shallow and deep sites was between $4-6 \mathrm{~ms}^{-2}$, whereas the intermediate depths recorded between $6-9 \mathrm{~ms}^{-2}$ (Fig. S6).

\section{Intraspecific interactions at different latitudes}

Intra-specific interactions along the latitudinal gradient revealed predominantly positive interactions across all latitudes and did not display a significant difference in interaction strength among latitudes during either spring $\left(\mathrm{p}=0.168\right.$, adjusted $\left.\mathrm{R}^{2}=0.145\right)$ or summer $(\mathrm{p}=$ 
0.269 adjusted $\mathrm{R}^{2}=0.052$, Fig. 2a, Fig. S6). Epiphyte cover varied among latitudes, but not in accordance with the latitudinal differences in temperature (Fig. 2b - c, Table 2). Consistent with long term profiles, summer temperatures were warmer at $32^{\circ} \mathrm{S}$ and $30^{\circ} \mathrm{S}$ than $34^{\circ} \mathrm{S}$, but did not consistently vary between canopy and canopy-free treatments (Fig. 2c, Table 2).

Despite differences in temperature among latitudes, nutrient levels remained relatively constant $\left(\mathrm{NO}_{3}\right.$ concentrations $\left.=0.8-1.5 \mu \mathrm{mol} \mathrm{L}{ }^{-1}\right)$ across all nine sites (Fig. S8). Light levels did not vary among latitudes but as in the depth experiment, mean illuminance under the canopy was significantly lower than in canopy-free treatments (Fig. 2d, Table 2). Patterns in light and temperature were consistent among mean, maximum, minimum (temperature only) and standard deviation (light only) measurements (Fig. S9 and S10).

\section{Generalities in intra-specific and inter-specific interactions}

Examining the nature of subtidal canopy interactions under low consumer pressure, across dominant species from around the world, revealed that positive and neutral interactions were widespread. Growth rates of seaweeds within the canopy were higher than canopy-free growth rates, resulting in net positive intra-specific interactions for five of the six species tested including three temperate kelp species from Australia (E. radiata) and South Africa (E. maxima and L. pallida), and temperate and tropical fucoids (subgen. Sargassum sp. and Sargassum illicifolium, respectively; Fig. 3a). Laminaria hyperborea, in populations from both France and Norway, was the only species to show net competitive intra-specific interactions.

Facilitation was less pronounced among inter-specific interactions in seaweed canopies.

Growth rates of kelp (L. pallida) and temperate fucoids (Scytothalia dorycarpa, Arthrophycus sp. and Sargassum sp.) species growing within kelp canopies displayed neutral interactions. 
329 In contrast, kelp, E. radiata, displayed positive interactions within temperate Sargassum sp. canopies while Sargassum decurrens, displayed net competitive interactions in tropical Sargassum illicifolium canopies (Fig. 3b).

\section{Discussion}

334 Our results revealed that positive and neutral canopy interactions are common within seaweed communities globally and that the nature of interactions can change in response to physical stress gradients in subtidal marine ecosystems where consumer pressure is low. Under benign light conditions below $8 \mathrm{~m}$ depth, canopy interactions were primarily competitive or neutral, whereas under shallow, high-light conditions seaweed growth became increasingly facilitated by the canopy. These findings provide support for the SGH and represent the first example of the SGH along a light-stress depth gradient that we are aware of. In contrast, interactions were neutral to positive and did not change along a latitudinal temperature gradient. While these findings do not support the SGH, they do not contradict it either, as canopy treatments were unable to consistently lower temperature conditions and alleviate temperature stress. These results were, however, consistent with interactions among nine dominant subtidal canopy species from around the world, where facilitation was the most common outcome of intra-specific interactions.

Light is a fundamental resource for plants and attenuates with depth in the ocean, limiting the vertical distribution of seaweeds (Staehr \& Wernberg 2009). In the upper depths of the ocean however, light is not a limiting resource, and high-light levels can act like a non-resource stress gradient (c.f. resource gradient; Maestre et al. 2009) whereby photosynthetically active 
radiation exceeds saturating levels (Altamirano et al. 2004) and ultra violet radiation can penetrate the water column and potentially damage kelp tissue (Wood 1987). The reduction of high-light conditions within the canopy at shallow depths appears to be fundamentally important to the health and growth of seaweed canopies. As light attenuates toward deeper depths, the dependence on neighbours reduces and interactions were observed to become neutral to competitive. Given canopies can only reduce light levels, not increase them, it would be expected that below the depths observed here, interactions would continue to become increasingly competitive as light becomes limiting toward a species vertical distribution limit. Indeed, this would explain the consistent thinning of canopies at deeper depths. Our findings are consistent with previous studies that examined recruitment patterns in response to canopy shading and observed primarily competitive interactions in depths between 10-18 m where canopy shading effects were similar to those observed here (Dayton et al. 1984; Reed \& Foster 1984).

While light conditions appear to be the dominant driver of interaction patterns, other nonstressful environmental gradients (sensu He \& Bertness 2014) were present and may have partially contributed to the nature of interactions. All depths experienced relatively high wave exposure, and no clear pattern between depth and water velocities were observed, suggesting that water velocity cannot explain the observed change in interactions with depth.

Nevertheless, the presence of a canopy can reduce drag on a thallus by over $80 \%$, compared to a solitary individual (Johnson 2001) enabling canopy kelps to attain greater size than solitary individuals in wave exposed areas (de Bettignies et al. 2013a), potentially promoting facilitation. Water movement also influences physical scour from the canopy and is likely to reduce the settlement and growth of epiphytes on kelp in the canopy. Interestingly, despite high wave exposure, temperatures changed both across the depth gradient and between canopy treatments, with slightly cooler temperatures recorded inside the canopy at some sites. 
377 Temperature differences among canopy treatments were, however, small in comparison to

378 differences among depths and very small relative to the temperature range of E. radiata.

379 Temperature is therefore unable to explain the interaction patterns observed along the depth

380 gradient.

381 Temperature also did not modify interaction patterns along the latitudinal temperature stress gradient, with positive interactions prevailing at five out of the six latitudinal experiments. These observations are consistent with canopy-recruit interactions observed for Scytothalia dorycarpa in the same region, however differ from canopy-recruit interactions for Sargassum sp. and Ecklonia radiata which have been observed to change from competitive to facilitative in response to latitudinal temperature gradients (Wernberg et al. 2010; Bennett \& Wernberg 2014). It remains unclear why some recruits change the nature of their interaction with the canopy along temperature gradients while adults do not, particularly given we observed that canopies did not modify temperatures sufficiently to reduce thermal stress. These results suggest that a combination of processes (i.e. light and temperature stress) can interact to determine interaction patterns in subtidal canopies (Wernberg et al. 2010), and that there may be ontogenetic changes in the nature of interactions within canopy species (He \& Bertness 2014).

In subtidal systems elsewhere, combined effects of warm temperatures and low nutrients have been shown to influence kelp interactions. The recovery of the competitively dominant giant kelp, Macrocystis pyrifera following storm events depends on low-frequency cycles in nutrient and temperature conditions in response to the El Niño Southern Oscillation, which in turn influences the recruitment and abundance patterns of subordinate kelp species (Dayton et al. 1999). M. pyrifera canopies have also been adversely affected by warm temperatures and low nutrient conditions in south-eastern Australia (Johnson et al. 2011), but E. radiata canopies have not, suggesting that $E$. radiata canopies may be more tolerant of low nutrient 

could increase nutrient supply within canopies, thereby supplementing local nutrient conditions within the canopy and promote facilitation (de Bettignies et al. 2013b). It is unclear whether the small-scale clearings used in our experiment, were large enough to modify local nutrient availability, nevertheless the North American example illustrates that multiple stressors can influence the nature of interactions and may help explain the variable responses observed along the temperature gradient.

The consistent pattern of neutral to positive interactions of Ecklonia radiata among latitudes is in agreement with observed global interaction patterns, where positive and neutral interactions were found to be widespread among multiple subtidal canopy types that experience low consumer pressure. Among the kelp species observed, Laminaria hyperborea in the North Atlantic was the only species to display negative interactions with the canopy, whereas Australian and South African kelps displayed primarily positive interactions. Light availability may have contributed to these patterns as French reefs in particular were generally deeper and had lower light (due to turbidity) than canopies observed in Australia and South Africa (Staehr \& Wernberg 2009). Life history traits may also help to explain the observed interaction patterns, particularly for Sargassum which displayed competitive interspecific interactions within the kelp canopy. Sargassum has a buoyant thallus that has adapted to fragment easily as a means of propagule dispersal (Schiel \& Foster 2006). Fragmentation of Sargassum by the abrasive canopy might have contributed to the lower net growth rates of Sargassum within the canopy, yet may assist its dispersal and reproductive success.

In addition to contemporary environmental processes influencing interactions, the stability of canopies over evolutionary time scales may contribute to the prevalence of positive interactions, particularly in southern Australian. Modern canopy seaweeds (orders 
427 Laminariales and Fucales) evolved during the Miocene (Silberfeld et al. 2010), since which 428 time the marine climate of southern Australia has been remarkably stable (McGowran et al. 1997). While the diversification of Australia's marine flora was likely to have begun prior to the arrival of canopy species (Hommersand 1986), the long climatically stable history of seaweed canopies in Australia and their dense cover on reefs is likely to have favoured adaptations among canopy and understory seaweeds to thrive within canopy conditions.

Collectively, our findings highlight that canopy interactions may have an important influence on the response of subtidal habitats to physical stress. Kelp forests are often thought to be resilient to disturbance due to their fast growth rates and rapid colonisation of space (Dayton et al. 1984; Steneck et al. 2002). Our results suggest that many seaweed communities may in fact be dependent on the surrounding canopy to ameliorate stressful abiotic conditions. On shallow reefs canopy loss could result in high-light conditions that inhibit kelp recovery, providing a positive feedback mechanism that reinforces a canopy-free state. Such scenarios may become increasingly common under climate change and may help to explain subtidal community changes, as were observed following a decline in seaweed canopy cover in

Western Australia in response to an extreme marine heatwave (Wernberg et al. 2013). Understanding the role of other abiotic stress gradients (i.e. wave exposure) and the additive or synergistic effects of multiple stressors on interactions in the subtidal will help to improve our understanding and management of subtidal communities in the face of such global changes. The stress gradient hypothesis provides a useful concept to address these questions and has been seldom applied in subtidal ecosystems to date (Bulleri 2009). Our results reveal that neutral to positive canopy interactions are widespread throughout subtidal ecosystems 449 globally and may be critical to reduce high-light stress in shallow subtidal marine systems.

450 These findings suggest that canopy interactions are important in sustaining the function of many seaweed dominated systems and could therefore provide critical information about 
community performance across major environmental gradients and in the face of contemporary changes to the physical environment in coastal marine ecosystems.

\section{Acknowledgements:}

The authors would like to acknowledge the assistance of Emily Gates, Anne Belot, Tomasz Pedlow, Brezo Martinez, Chenae Tuckett, Maria Cabrero Llorente, Stefan Andrews, Andrea Zavala Perez, Mark Rothman, Derek Kemp, Chris Boothroyd, Yann Fontana, Wilfried Thomas and Mathieu Camusat for their assistance in the field and laboratory. We would also like to thank Paul Dayton, Jon Witman, Robert Scheibling and Neville Barrett for valuable feedback on the manuscript. Funding for this work was provided by the Australian Research Council (TW), The University of Western Australia Research Collaboration Awards (TW, GAK, TdB, JB, RA, JCL, LL, DD, HC), The Worldwide Universities Network Research Development fund (TW, GAK, JJB, RJA), the France-Australia Science Innovation Collaboration 2014 program (TdB, TW, JCL, LL, DD), the National Research Foundation, South Africa (JJB, RJA, TW), the French Government run by the National Research Agency and with regards to the investment expenditure programme IDEALG ANR-10-BTBR-04 (JCL, LL, DD), and a UWA Post Graduate Research Travel Award (SB).

\section{References:}

1.

Aberg, P. (1990). Measuring size and choosing category size for a transition matrix study of the seaweed Ascophyllum nodosum. Marine Ecology Progress Series, 63, 281-287.

2. 
475 Altamirano, M.a., Murakami, A. \& Kawai, H. (2004). High light stress in the kelp Ecklonia cava. Aquatic Botany, 79, 125-135.

477

3.

478

Anderson, M.J. (2008). Animal-sediment relationships re-visited: Characterising species' distributions along an environmental gradient using canonical analysis and quantile regression splines. Journal of Experimental Marine Biology and Ecology, 366, 16-27.

4.

482

Anderson, R.J., Carrick, P., Levitt, G.J. \& Share, A. (1997). Holdfasts of adult kelp Ecklonia

5.

7.

8.

Berec, L., Angulo, E. \& Courchamp, F. (2007). Multiple Allee effects and population management. Trends in Ecology \& Evolution, 22, 185-191.

497

9. 
500

501

502

503

504

505

506

507

508

509

510

511

512

513

514

515

516

517

518

Bertness, M.D. \& Callaway, R. (1994). Positive interactions in communities. Trends in Ecology \& Evolution, 9, 191-193.

10.

Bruno, J.F., Stachowicz, J.J. \& Bertness, M.D. (2003). Inclusion of facilitation into ecological theory. Trends in Ecology \& Evolution, 18, 119-125.

11.

Bulleri, F. (2009). Facilitation research in marine systems: state of the art, emerging patterns and insights for future developments. Journal of Ecology, 97, 1121-1130.

12.

Bulleri, F., Cristaudo, C., Alestra, T. \& Benedetti-Cecchi, L. (2011). Crossing gradients of consumer pressure and physical stress on shallow rocky reefs: a test of the stressgradient hypothesis. Journal of Ecology, 99, 335-344.

13.

Cavieres, L.A., Brooker, R.W., Butterfield, B.J., Cook, B.J., Kikvidze, Z., Lortie, C.J. et al. (2014). Facilitative plant interactions and climate simultaneously drive alpine plant diversity. Ecology Letters, 17, 193-202.

14.

Critchley, A.T., Devisscher, P.R.M. \& Nienhuis, P.H. (1990). Canopy characteristics of the brown alga Sargassum muticum (Fucales, Phaeophyta) in Lake Grevelingen, southwest Netherlands. Hydrobiologia, 204, 211-217.

15. 
519

520

521

522

523

524

525

526

527

528

529

530

531

532

533

534

535

536

537

538

539

540

Dayton, P.K., Currie, V., Gerrodette, T., Keller, B.D., Rosenthal, R. \& Tresca, D.V. (1984). Patch dynamics and stability of some california kelp communities. Ecological Monographs, 54, 254-289.

16.

Dayton, P.K., Tegner, M.J., Edwards, P.B. \& Riser, K.L. (1999). Temporal and spatial scales of kelp demography: the role of oceanographic climate. Ecological Monographs, 69, 219-250.

17.

de Bettignies, T., Wernberg, T. \& Lavery, P.S. (2013a). Size, not morphology, determines hydrodynamic performance of a kelp during peak flow. Marine Biology, 160, 843851.

18.

de Bettignies, T., Wernberg, T., Lavery, P.S., Vanderklift, M.A. \& Mohring, M.B. (2013b). Contrasting mechanisms of dislodgement and erosion contribute to production of kelp detritus. Limnology and Oceanography, 58, 1680-1688.

19.

Duarte, C.M. (1991). Seagrass depth limits. Aquatic Botany, 40, 363-377.

20.

Evans, S. \& Abdo, D. (2010). A cost-effective technique for measuring relative water movement for studies of benthic organisms. Marine and Freshwater Research, 61, 1327-1335.

21. 
541 Hay, M.E. (1986). Associational plant defenses and the maintenance of species diversity: turning competitors into accomplices. American Naturalist, 617-641.

543

22.

544 He, Q. \& Bertness, M.D. (2014). Extreme stresses, niches and positive species interactions 545 along stress gradients. Ecology.

546

23.

547 He, Q., Bertness, M.D. \& Altieri, A.H. (2013). Global shifts towards positive species interactions with increasing environmental stress. Ecology Letters, 16, 695-706.

549

24.

550

Hommersand, M. (1986). The biogeography of the South African marine red algae: a model.

551 Bot. Marina, 29, 257-270.

552

25.

553

Johnson, A.S. (2001). Drag, drafting, and mechanical interactions in canopies of the red alga Chondrus crispus. The Biological Bulletin, 201, 126-135.

555

26.

556

557

558

559

560

27.

561 Kikvidze, Z., Pugnaire, F.I., Brooker, R.W., Choler, P., Lortie, C.J., Michalet, R. et al. (2005). Linking patterns and processes in alpine plant communities: a global study. Ecology, 86, 1395-1400. 
565 Kitching, J.A. (1941). Studies in sublittoral ecology III Laminaria forest on the west coast of Scotland, a study of zonation in relation to wave action and illumination. Biological Bulletin, 80, 324-337.

568

29.

569

570

571

572

573

574

575

576

577

Kohler, K.E. \& Gill, S.M. (2006). Coral Point Count with Excel extensions (CPCe): A Visual Basic program for the determination of coral and substrate coverage using random point count methodology. Computers and Geosciences, 32, 1259-1269.

30.

Kordas, R.L., Harley, C.D.G. \& O'Connor, M.I. (2011). Community ecology in a warming world: The influence of temperature on interspecific interactions in marine systems. Journal of Experimental Marine Biology and Ecology, 400, 218-226.

31.

Long, M.H., Rheuban, J.E., Berg, P. \& Zieman, J.C. (2012). A comparison and correction of light intensity loggers to photosynthetically active radiation sensors. Limnology \& Oceanography Methods, 10, 416-424.

32.

Lüning, K. (1984). Temperature tolerance and biogeography of seaweeds: the marine algal flora of Helgoland (North Sea) as an example. Helgoländer Meeresuntersuchungen, 38, 305-317.

33. 
600

601

602

603

604

605 606

Maestre, F.T., Callaway, R.M., Valladares, F. \& Lortie, C.J. (2009). Refining the stressgradient hypothesis for competition and facilitation in plant communities. Journal of Ecology, 97, 199-205.

34.

Marzinelli, E.M., Williams, S.B., Babcock, R.C., Barrett, N.S., Johnson, C.R., Jordan, A. et al. (2015). Large-Scale Geographic Variation in Distribution and Abundance of Australian Deep-Water Kelp Forests. PloS one, 10, e0118390.

35.

McGowran, B., Li, Q., Cann, J., Padley, D., McKirdy, D.M. \& Shafik, S. (1997). Biogeographic impact of the Leeuwin Current in southern Australia since the late middle Eocene. Palaeogeography, Palaeoclimatology, Palaeoecology, 136, 19-40.

36.

Peterson, B.J. \& Heck, K.L. (2001). Positive interactions between suspension-feeding bivalves and seagrass - a facultative mutualism. Marine Ecology Progress Series, 213, 143-155.

37.

Reed, D.C. \& Foster, M.S. (1984). The effects of canopy shading on algal recruitment and growth in a giant-kelp forest. Ecology, 65, 937-948.

38.

Rodgers, K.L., Rees, T.A.V. \& Shears, N.T. (In press). A novel system for measuring in situ rates of photosynthesis and respiration of kelps. Marine Ecology Progress Series.

39. 
Schiel, D.R. \& Foster, M.S. (2006). The population biology of large brown seaweeds: Ecological consequences of multiphase life histories in dynamic coastal environments. Annu. Rev. Ecol. Evol. Syst., 37, 343-372.

40.

Siddon, C.E. \& Witman, J.D. (2003). Influence of chronic, low-level hydrodynamic forces on subtidal community structure. Marine ecology. Progress series, 261, 99-110.

41.

Silberfeld, T., Leigh, J.W., Verbruggen, H., Cruaud, C., De Reviers, B. \& Rousseau, F. (2010). A multi-locus time-calibrated phylogeny of the brown algae (Heterokonta, Ochrophyta, Phaeophyceae): Investigating the evolutionary nature of the "brown algal crown radiation”. Molecular Phylogenetics and Evolution, 56, 659-674.

42.

Smale, D.A. \& Wernberg, T. (2009). Satellite-derived SST data as a proxy for water temperature in nearshore benthic ecology. Marine Ecology Progress Series, 387, $27-$ 37.

43.

Stachowicz, J.J. \& Hay, M.E. (1999). Reducing predation through chemically mediated camouflage: Indirect effects of plant defenses on herbivores. Ecology, 80, 495-509.

44.

Staehr, P.A. \& Wernberg, T. (2009). Physiological responses of Ecklonia radiata (laminariales) to a latitudinal gradient in ocean temperature. Journal of Phycology, 45, 91-99.

45. 
Steneck, R.S., Graham, M.H., Bourque, B.J., Corbett, D., Erlandson, J.M., Estes, J.A. et al. (2002). Kelp forest ecosystems: biodiversity, stability, resilience and future. Environmental Conservation, 29, 436-459.

46.

Wernberg, T., Kendrick, G.A. \& Toohey, B.D. (2005). Modification of the physical environment by an Ecklonia radiata (Laminariales) canopy and implications for associated foliose algae. Aquat. Ecol., 39, 419-430.

47.

Wernberg, T., Smale, D.A., Tuya, F., Thomsen, M.S., Langlois, T.J., de Bettignies, T. et al. (2013). An extreme climatic event alters marine ecosystem structure in a global biodiversity hotspot. Nature Climate Change, 3, 78-82.

48.

Wernberg, T., Thomsen, M.S., Tuya, F., Kendrick, G.A., Staehr, P.A. \& Toohey, B.D. (2010). Decreasing resilience of kelp beds along a latitudinal temperature gradient: potential implications for a warmer future. Ecology Letters, 13, 685-694.

49.

Witman, J.D. (1987). Subtidal coexistence - storms, grazing, mutualism, and the zonation of kelps and mussels. Ecological Monographs, 57, 167-187.

50.

Wood, W. (1987). Effect of solar ultra-violet radiation on the kelp Ecklonia radiata. Marine Biology, 96, 143-150.

\section{Figure captions}


653 Figure 1: Nature of intra-specific interactions of Ecklonia radiata along a subtidal depth 654 gradient from 3 - 19 m. (a) Relative Interaction Index (RII) of E. radiata based on mean 655 growth rates in canopy and canopy-free treatments. Positive values from 0 to 1 indicate 656 increasingly facilitative net interactions and negative values from 0 to -1 indicate increasingly 657 competitive net interactions. (b) Comparison of kelp health based on mean epiphytic cover of 658 secondary laterals after the two month experimental period with (dark grey) and without 659 (open) canopy ( $\mathrm{n}=10$ kelps per treatment). (c) Mean light illuminance recorded with and without canopy between the hours 0800 - 1600 for 14 days among the different depths. (d) Mean, maximum and minimum temperatures recorded with and without canopy over the 2 month experimental period among the different depths

Figure 2: Nature of intra-specific interactions of Ecklonia radiata among nine sites along a subtidal latitudinal gradient from $34^{\circ} \mathrm{S}-30^{\circ} \mathrm{S}$. (a) Relative Interaction Index (RII) of $E$. radiata based on mean growth rates in canopy and canopy-free treatments. Positive values from 0 to 1 indicate increasingly facilitative net interactions and negative values from 0 to -1 indicate increasingly competitive net interactions. (b) Comparison of kelp health based on mean epiphyte cover of secondary laterals after the two month experimental period with (dark grey) and without (open) canopy ( $\mathrm{n}=10$ kelps per treatment). (c) Mean temperatures recorded with and without canopy over the 2 month experimental period among the different latitudes (d) Mean light illuminance recorded with and without canopy between the hours 0800 - 1600 for 14 days among the different latitudes.

Figure 3: Patterns in intra-specific (a) and inter-specific (b) interactions between dominant subtidal benthic habitat forming species from around the world. Positive values from 0 to 1 
677 indicate increasingly facilitative net interactions and negative values from 0 to -1 indicate

678 increasingly competitive net interactions. Numbers underneath the species name indicate the 679 number of replicate reefs where each interaction type was measured. Sites range between 6$68012 \mathrm{~m}$ depth except tropical Sargassum sites which were recorded in 3-4 m depth (Table S1).

681

682

683 
Table 1: Results of ANCOVA models comparing Growth, Epiphyte cover, Illuminance and

685

Temperature, between canopy treatments along the depth gradient. Epiphyte cover was

686 arcsin-square root transformed and illuminance was log10 transformed.

687

\begin{tabular}{|c|c|c|c|c|c|}
\hline \multirow[t]{5}{*}{ Growth } & & Estimate & Std. Error & t value & $\operatorname{Pr}(>|t|)$ \\
\hline & (Intercept) & 3.14928 & 0.361 & 8.722 & 0.000 \\
\hline & Canopy treatment (CT) & -0.816 & 0.515 & -1.583 & 0.115 \\
\hline & Depth & -0.030 & 0.029 & -1.028 & 0.305 \\
\hline & CT:Depth & 0.089 & 0.042 & 2.133 & 0.034 \\
\hline \multirow[t]{5}{*}{ Epiphyte cover } & & Estimate & Std. Error & t value & $\operatorname{Pr}(>|t|)$ \\
\hline & (Intercept) & 0.156 & 0.062 & 2.530 & 0.013 \\
\hline & Canopy treatment (CT) & 0.784 & 0.091 & 8.589 & 0.000 \\
\hline & Depth & -0.006 & 0.005 & -1.170 & 0.244 \\
\hline & CT:Depth & -0.051 & 0.008 & -6.506 & 0.000 \\
\hline \multirow[t]{5}{*}{ Illuminance (Lux) } & & Estimate & Std. Error & t value & $\operatorname{Pr}(>|t|)$ \\
\hline & (Intercept) & 2.888 & 0.061 & 47.429 & 0.000 \\
\hline & Canopy treatment (CT) & 1.446 & 0.083 & 17.443 & 0.000 \\
\hline & Depth & -0.036 & 0.005 & -7.024 & 0.000 \\
\hline & CT:Depth & -0.005 & 0.007 & -0.737 & 0.462 \\
\hline \multirow[t]{5}{*}{ Temperature $\left({ }^{\circ} \mathrm{C}\right)$} & & Estimate & Std. Error & t value & $\operatorname{Pr}(>|t|)$ \\
\hline & (Intercept) & 21.394 & 0.074 & 290.516 & 0.000 \\
\hline & Canopy treatment (CT) & 0.222 & 0.100 & 2.219 & 0.027 \\
\hline & Depth & -0.032 & 0.006 & -5.193 & 0.000 \\
\hline & CT:Depth & -0.015 & 0.008 & -1.908 & 0.057 \\
\hline
\end{tabular}

688

689 
Table 2: Results of ANCOVA models comparing Relative interaction index between seasons

691 along a latitudinal gradient, Epiphyte cover, Illuminance and Temperature, between canopy

692 treatments along a latitudinal gradient. Epiphyte cover was arcsin-square root transformed

693 and illuminance was square root transformed.

\begin{tabular}{|c|c|c|c|c|c|}
\hline \multirow[t]{5}{*}{ RII } & & Estimate & Std. Error & t value & $\operatorname{Pr}(>|t|)$ \\
\hline & (Intercept) & 0.956 & 0.935 & 1.022 & 0.325 \\
\hline & Season & -0.026 & 1.322 & -0.020 & 0.985 \\
\hline & Latitude & -0.026 & 0.029 & -0.876 & 0.397 \\
\hline & Season:Latitude & -0.003 & 0.041 & -0.085 & 0.934 \\
\hline \multirow[t]{5}{*}{ Epiphyte cover } & & Estimate & Std. Error & t value & $\operatorname{Pr}(>|t|)$ \\
\hline & (Intercept) & 1.018 & 0.262 & 3.892 & 0.000 \\
\hline & Canopy treatment (CT) & -0.523 & 0.374 & -1.400 & 0.163 \\
\hline & Latitude & -0.024 & 0.008 & -2.918 & 0.004 \\
\hline & CT:Latitude & 0.018 & 0.012 & 1.553 & 0.122 \\
\hline \multirow[t]{5}{*}{ Illuminance (Lux) } & & Estimate & Std. Error & t value & $\operatorname{Pr}(>|t|)$ \\
\hline & (Intercept) & 52.198 & 25.324 & 2.061 & 0.040 \\
\hline & Canopy treatment (CT) & 103.286 & 35.813 & 2.884 & 0.004 \\
\hline & Latitude & 1.177 & 0.790 & 1.490 & 0.138 \\
\hline & CT:Latitude & 1.600 & 1.118 & 1.431 & 0.154 \\
\hline \multirow[t]{5}{*}{ Temperature $\left({ }^{\circ} \mathrm{C}\right)$} & & Estimate & Std. Error & t value & $\operatorname{Pr}(>|t|)$ \\
\hline & (Intercept) & 37.012 & 0.658 & 56.289 & 0.000 \\
\hline & Canopy treatment (CT) & -0.761 & 0.930 & -0.819 & 0.413 \\
\hline & Latitude & 0.425 & 0.021 & 20.565 & 0.000 \\
\hline & CT:Latitude & -0.026 & 0.029 & -0.888 & 0.375 \\
\hline
\end{tabular}




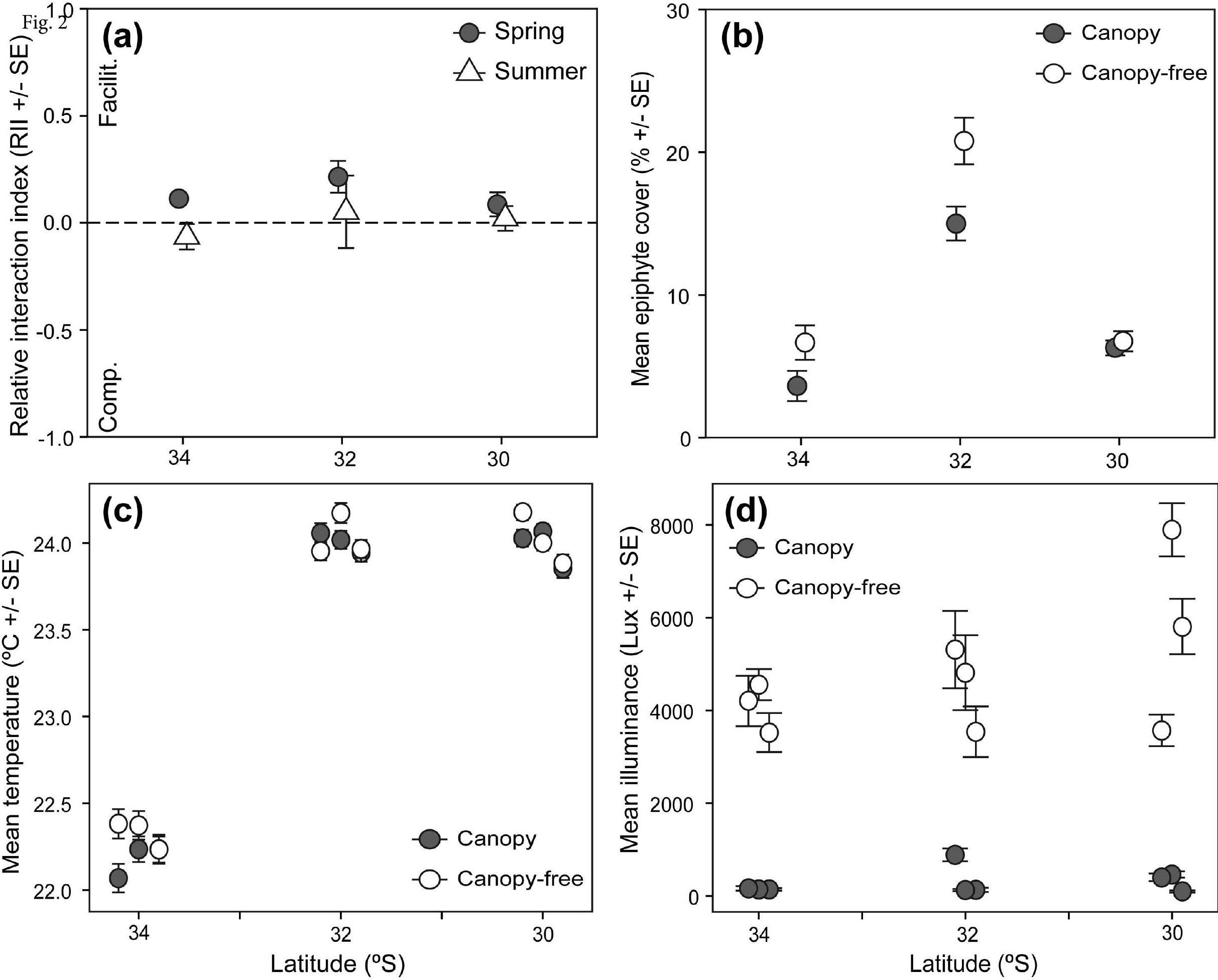




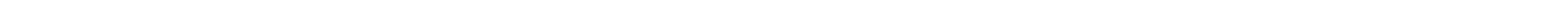

